\title{
Epidemiology of Thyroid Dysgenesis: The Familial Component
}

\author{
Mireille Castanet ${ }^{\mathrm{a}}$ Daniela Marinovic $^{\mathrm{b}}$ Michel Polak $^{\mathrm{a}} \quad$ Juliane Léger $^{\mathrm{b}}$ \\ a Paediatric Endocrinology Unit and INSERM U363, Hôpital Necker Enfants-Malades, et b Paediatric Endocrinology \\ Unit and INSERM U 690, Hôpital Robert-Debré, Centre de Reference Maladies Endocriniennes de la Croissance, \\ Paris, France
}

\section{Key Words}

Congenital hypothyroidism • Thyroid dysgenesis •

Athyreosis - Thyroid hypoplasia - Ectopic thyroid gland ·

Cyst of thyroglossal duct $\cdot$ Pyramidal lobe $\cdot$ Familial component

\begin{abstract}
The pathophysiology of thyroid dysgenesis remains unclear and, until recently, this disorder was generally regarded as sporadic. However, a small but significant proportion of familial cases have been identified (2\%) through the study of subjects with congenital hypothyroidism, and more recent work has revealed an even higher proportion of familial thyroid dysgenesis in both symptomatic and asymptomatic individuals. These studies strongly suggest the existence of a familial component of this disorder involving dominant genetic predisposition factors with a low penetrance.
\end{abstract}

Copyright $\odot 2010$ S. Karger AG, Basel

\section{Introduction}

Most cases of permanent congenital hypothyroidism $(\mathrm{CH})$ are related to thyroid dysgenesis (TD) due to abnormal thyroid gland development involving various embryogenic defects, such as ectopic thyroid gland, athyreosis and thyroid hypoplasia [1]. Other more frequent asymptomatic variations of thyroid anatomy, such as cysts of the thyroglossal duct, additional thyroid tissue (pyramidal lobe) and hemiagenesis, have also been reported, often in subjects with normal thyroid function [2]. About $5 \%$ of the cases have been shown to result from mutations in genes known to be involved in thyroid development [3], but most cases of TD are sporadic and their pathogenesis remains unknown. A high frequency of other congenital defects, mostly cardiac, has been reported, supporting the role of a genetic component in this disease $[1,4]$, and previous reports of some familial cases of $\mathrm{CH}$ due to TD resulting from athyreosis [5-7] or an ectopic gland [8-10] are also consistent with the notion of an inherited disease. We report here the prevalence and clinical characteristics of familial forms of thyroid dysgenesis found in two recent French family-based studies [11, 12]. The precise phenotypic characterization of these patients should provide insight into the mechanisms underlying abnormal thyroid development.

\section{KARGER \\ Fax +4161306 1234 E-Mail karger@karger.ch} www.karger.com

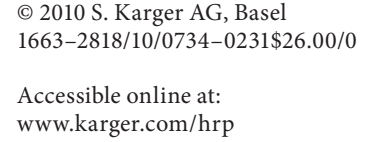

Centre de Reference Maladies Endocriniennes de la Croissance, Hôpital Robert-Debré Paediatric Endocrinology Unit, INSERM U690, 48, Bd Serurier FR-75019 Paris (France)

Tel. +33 1400323 54, Fax +331 400324 29, E-Mail juliane.leger@ rdb.aphp.fr 
Fig. 1. Thyroid gland embryology [1].

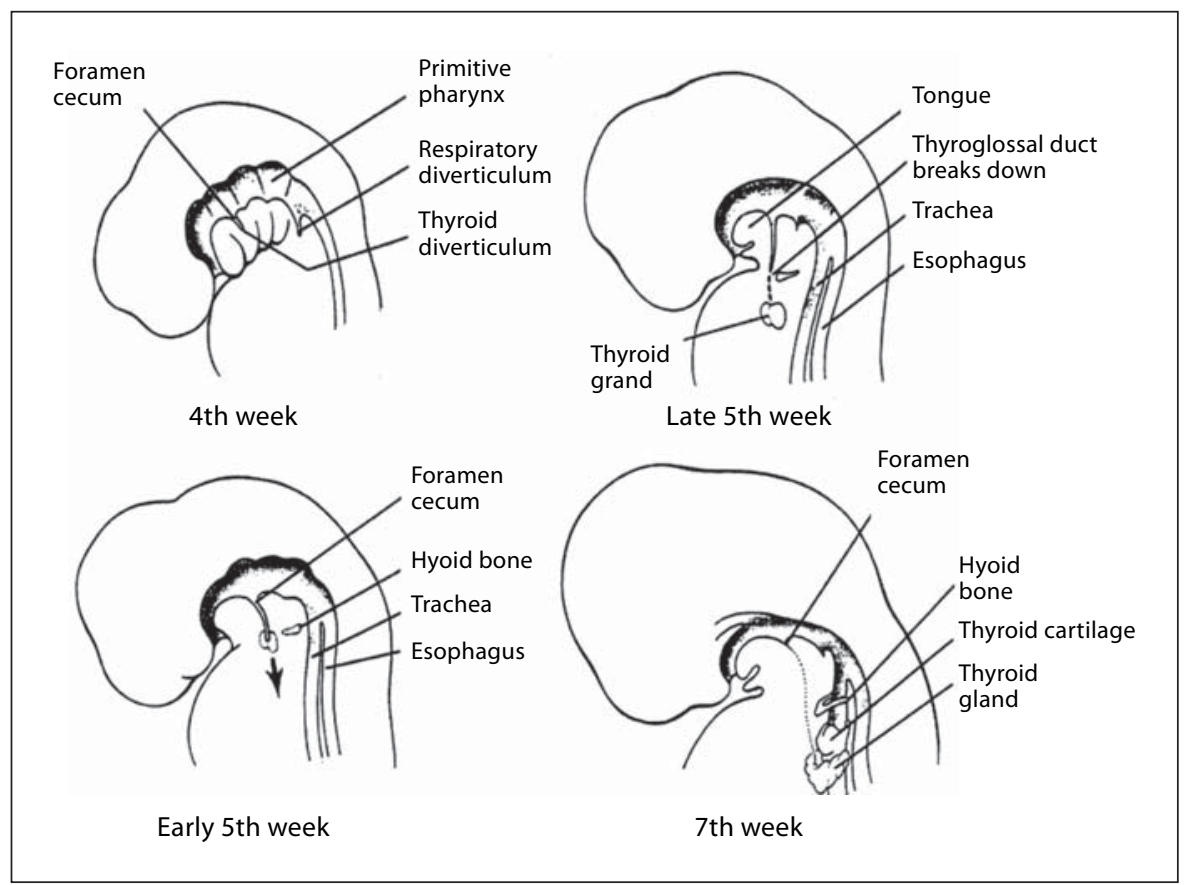

\section{Thyroid Development}

In the human embryo, the thyroid gland primordium first appears late in the fourth week, in the midline of the floor of the primitive pharynx, at a point subsequently called the foramen cecum, on the developing tongue. This initially round cluster of cells then begins to migrate from the pharyngeal floor, through the anterior midline of the neck. The cells multiply during this migration and, after 24-32 days, this median anlage has already become a bilobed structure. However, it reaches its final position only after about 48-50 days. The connection of the median anlage with the ultimobranchial body, which develops from the endoderm of the 4th pharyngeal pouch, occurs at the same time, resulting in the incorporation of the $\mathrm{C}$ cells into the thyroid. At 51 days, the gland takes on its definitive external form, with an isthmus connecting the two lateral lobes. It reaches its final position below the thyroid cartilage by the seventh week of embryonic development. During its descent, the developing thyroid gland remains attached to the pharynx by a narrow epithelial stalk known as the thyroglossal duct [13]. By day 37 , this structure, which connects the median thyroid anlage to the point on the floor of the pharynx from which it starts to migrate, has generally disappeared [14]. The foramen cecum itself is generally the only remnant of the thyroglossal duct (fig. 1).
The terminal differentiation of thyroid follicular cells (as demonstrated by expression of the genes encoding the TSH receptor (TSHR), the Na/I symporter (NIS), thyroglobulin (Tg) and thyroperoxidase (TPO)) and follicles formation usually occur in the normal embryo only after the completion of migration [15]. However, thyroid function has been observed in children with ectopic thyroid tissue and a few ectopic thyroids have been examined under the microscope and shown to contain follicular structures, suggesting that follicles may develop even if migration is interrupted [16].

\section{Different Types of Thyroid Dysgenesis}

Most $\mathrm{CH}$ patients with thyroid dysgenesis have a defect in thyroid migration resulting in the presence of ectopic thyroid tissue ( $\sim 65 \%$ of $\mathrm{CH}$ patients). This arrest of the normal descent of part or all of the thyroid gland may result in thyroid tissue being present in a lingual, suprahyoid or infrahyoid location. Ectopic thyroid tissue is most frequently found at the base of the tongue. Doubleectopic thyroid tissues, with both lingual and sublingual tissues, have also been reported in rare cases [17]. Ectopic thyroid tissue generally leads to congenital hypothyroidism, but, such tissues are discovered incidentally in some asymptomatic subjects, raising the possibility that many 
cases are never diagnosed [18]. For example, an analysis of 200 consecutive necropsies on euthyroid Caucasian individuals showed that $10 \%$ of this population had ectopic lingual thyroid tissue of variable size, ranging from a few acini (undetectable on ultrasound scan) to a nodule one centimeter in diameter, with a similar frequency in men and women [19]. The absence of symptoms in some subjects suggests that the ectopic thyroid tissues may function normally. This hypothesis is supported by the finding of typical colloid-filled follicles on microscopy following the surgical removal and the uptake of radioactive iodine on scintiscan [20]. Moreover, although the thyroxine-producing capacity of patients with ectopic thyroid tissue is generally limited, it appears to remain constant, suggesting that the postnatal survival of ectopic cells is normal [16].

The second most common variant of TD $(\sim 30 \%)$ is the absence of detectable thyroid follicular cells (commonly called athyreosis, although this designation is not entirely correct because these patients, like those with ectopic thyroids, have functional $\mathrm{C}$ cells). It remains unknown whether thyroid follicular cells disappear through apoptosis after initial differentiation (as demonstrated in knockout mice) or fail to differentiate. Developmental failure of this type may affect only one lobe of the gland, resulting in hemiagenesis with or without an isthmus. More rarely, it may involve most, but not all of the follicular cells, resulting in highly hypoplastic glands in a normal position. These small glands may display such low levels of function that they are undetectable by nuclear medicine. In such cases of apparent athyreosis, careful analysis of ultrasound scans of the neck may reveal a very small thyroid gland of normal shape, in the orthotopic position. Scintiscan often fails to detect thyroid tissue in patients with severe thyrotropin resistance due to a complete loss of TSH receptor function [21, 22]. There may therefore be a certain degree of misclassification and accurate diagnosis of athyreosis therefore requires thyroid scintigraphy of a sufficiently high quality with-high definition ultrasonography. Serum thyroglobulin concentrations below the detection threshold in hypothyroid subjects may also provide an additional clue in cases of athyreosis [23].

Other abnormalities of thyroid development may also include persistence of the thyroglossal duct, giving rise to 'thyroglossal duct cysts', which generally become clinically apparent during infancy or childhood. Alternatively, cell residues may remain, giving rise to a pyramidal lobe at the distal portion of the duct, which remains attached to the thyroid gland, usually to the left lobe [14,
24]. Cysts have also been found within the empty thyroid bed in $\mathrm{CH}$ patients with $\mathrm{TD}$, consistent with the possible cystic degeneration of clusters of thyroid follicular cells that have completed their normal migration, even when the thyroid gland has otherwise remained descended incompletely or has entirely disappeared $[17,25]$. Other adjacent developmental abnormalities have also been reported, such as the presence of additional thymic tissue within the empty thyroid bed in patients with either ectopic thyroid tissue or athyreosis [26].

The two major forms of TD - ectopic thyroid gland and athyreosis - are often associated with congenital hypothyroidism, whereas other variations, as outlined above, are usually found in asymptomatic subjects with normal thyroid function, making it difficult to predict their true incidence. Thyroid hemiagenesis and a pyramidal lobe are generally discovered incidentally in patients with other thyroid disorders, when thyroid ultrasound scans or scintigraphy are performed [24,27]. Only one study to date has reported a prevalence for thyroid hemiagenesis $(\approx 0.2 \%)$, obtained by systematic ultrasound investigations in normal children [28]. Thyroglossal duct cysts are usually diagnosed on the basis of the presence of an asymptomatic neck mass, acute infection, chronic inflammation or hemorrhage; these cysts account for approximately $70 \%$ of congenital neck abnormalities [29].

\section{Familial Forms of Congenital Hypothyroidism due to Thyroid Dysgenesis}

A thorough literature review of publications over the last 40 years revealed that almost 20 multiplex families, each with several individuals presenting $\mathrm{CH}$ due to TD, have been described in various countries, suggesting that TD may be a familial disease in some instances [5-10]. A French national survey was therefore carried out in 1999, to test this hypothesis. In this survey of more than 2,500 $\mathrm{CH}$ patients with TD diagnosed in France between 1980 and 1998,67 patients with a positive family history of $\mathrm{CH}$ with TD from 32 multiplex families (i.e. with at least two affected members) were referred. Based on these data, the prevalence of familial cases was estimated at $2 \%$. Statistical analysis also showed that the number of cases of $\mathrm{CH}$ with TD among first-degree relatives was significantly higher (15 times higher) than expected from chance alone, consistent with a significant familial component $[1,11]$. 
The pedigrees of the families studied are shown in figure 2. Most of the families had two affected members $(\mathrm{n}=30)$, one family had three affected members, and another had four affected members. The first-degree relatives affected $(n=23)$ were siblings in 13 families and parents or children in 10 families. The affected relatives were more distantly related in the other 9 families: first cousins in six families, second cousins in one family and even more distant relatives in two families. This high proportion of transmissions from parents to offspring, including possible transmission from father to son in two cases, is consistent with an autosomal-dominant mode of inheritance with incomplete penetrance. However, these patterns of transmission could also be accounted for by genetic heterogeneity [1].

These families also provide important information about the etiology of TD. Some familial CH cases displayed athyreosis ( $\mathrm{n}=7$ families) or ectopic thyroid gland ( $\mathrm{n}=12$ families) alone, but 13 families displayed both athyreosis and ectopic thyroid gland (fig. 2). Moreover, in some families with at least two other members presenting either athyreosis or ectopic thyroid gland, some individuals with $\mathrm{CH}$ and a eutopic thyroid gland were identified. These findings suggest a common underlying mechanism for defects in embryogenic migration, differentiation or thyroid gland growth during thyroid organogenesis.

The reported preponderance of female over male cases was confirmed for isolated $\mathrm{CH}$ due to $\mathrm{TD}$, but the female: male ratio was significantly lower for familial cases (1.4 vs. $2.7 ; \mathrm{p}<0.03)$. Furthermore, if we also consider the etiology of TD, the female:male ratio was significantly lower for familial than for isolated cases for $\mathrm{CH}$ with athyreosis ( 0.9 vs. 2.7 ), whereas the difference in female:male ratio between familial and isolated cases was not significant for $\mathrm{CH}$ with ectopic thyroid gland (1.9 vs. 2.7). These data suggest a possible role for sex-dependent etiological factors in familial cases, particularly for athyreosis.

Thus, this familial study demonstrated for the first time that TD revealed by $\mathrm{CH}$ has a significant familial component, and that there may be a common mechanism underlying athyreosis and ectopic thyroid gland. Although unidentified common environmental factors cannot be ruled out, this report strongly suggested that genetic factors contribute to the risk of thyroid dysgenesis and that these factors may be affected by the sex of the subject. However, marked clinical variability both within and between families may reflect genetic heterogeneity, and further genetic studies are required to elucidate the physiopathology of thyroid defects.

\section{Familial Forms of Thyroid Dysgenesis in First-Degree Relatives of Children with Congenital Hypothyroidism}

As some thyroid tract abnormalities may be totally asymptomatic and multiplex families including subjects with major forms (i.e. $\mathrm{CH}$ ) [1], asymptomatic forms (TDA) [30] or both have been identified [8, 31], a further study was performed to determine whether the prevalence of familial cases of TD was higher than previously reported, to provide further evidence for a familial disease. Systematic screening was carried out, by neck ultrasound scans and the determination of serum TSH and FT4 concentrations, in all first-degree relatives of 84 children with $\mathrm{CH}$ and TD. If ectopic or additional thyroid tissue was detected on ultrasound scan, radioiodine thyroid scanning (radioactive iodide $123 \mathrm{I}$ ) was performed to identify functional thyroid tissue. In total, 241 first-degree relatives of the 84 studied patients underwent screening. Nineteen relatives (7.9\% of cases) from 18 families ( $21 \%$ of the studied families) had TDA (i.e. with no clinical complaints and serum free thyroid hormone and TSH concentrations in the normal range). The proportion of affected individuals among the firstdegree relatives of patients with $\mathrm{CH}$ and TD was significantly higher than that in the control population (7.9 vs. $0.9 \% ; \mathrm{p}<0.001$ ), consistent with a familial disorder [12]. As shown in the figure 3, the 19 subjects with TDA had a total of 21 detected abnormalities, with two subjects presenting two different abnormalities, hemiagenesis and thyroglossal duct cyst in one case, and additional thyroid tissue and thyroglossal duct cyst in the other. Thyroglossal duct cysts were the most frequent abnormality in subjects with TDA; they were found in 14 subjects ( 7 males, 7 females), who were the siblings $(\mathrm{n}=6)$ or parents $(\mathrm{n}=8)$ of 13 children with $\mathrm{CH}$ and ectopic thyroid tissue $(n=5)$, athyreosis $(n=7)$ or hemiagenesis $(\mathrm{n}=1)$. In all 14 of these subjects, the thyroid gland was located in its normal position. Additional thyroid tissue, in the form of a pyramidal lobe along the left lobe of the normally located thyroid gland, was found in three mothers of children with $\mathrm{CH}$ and ectopic thyroid tissue. Thyroid hemiagenesis with a single, correctly located lobe (left $\mathrm{n}=2$, right $\mathrm{n}=1$ ) was found in three siblings ( 2 boys, 1 girl) of 3 children with $\mathrm{CH}$ and ectopic thyroid tissue. Surprisingly, a cervical ectopic thyroid gland was found in a healthy, clinically and biologically euthyroid sister of one $\mathrm{CH}$ child with athyreosis, in whom no trace of thyroid tissue in the normal location could be detected on ultrasound scan. This ob- 


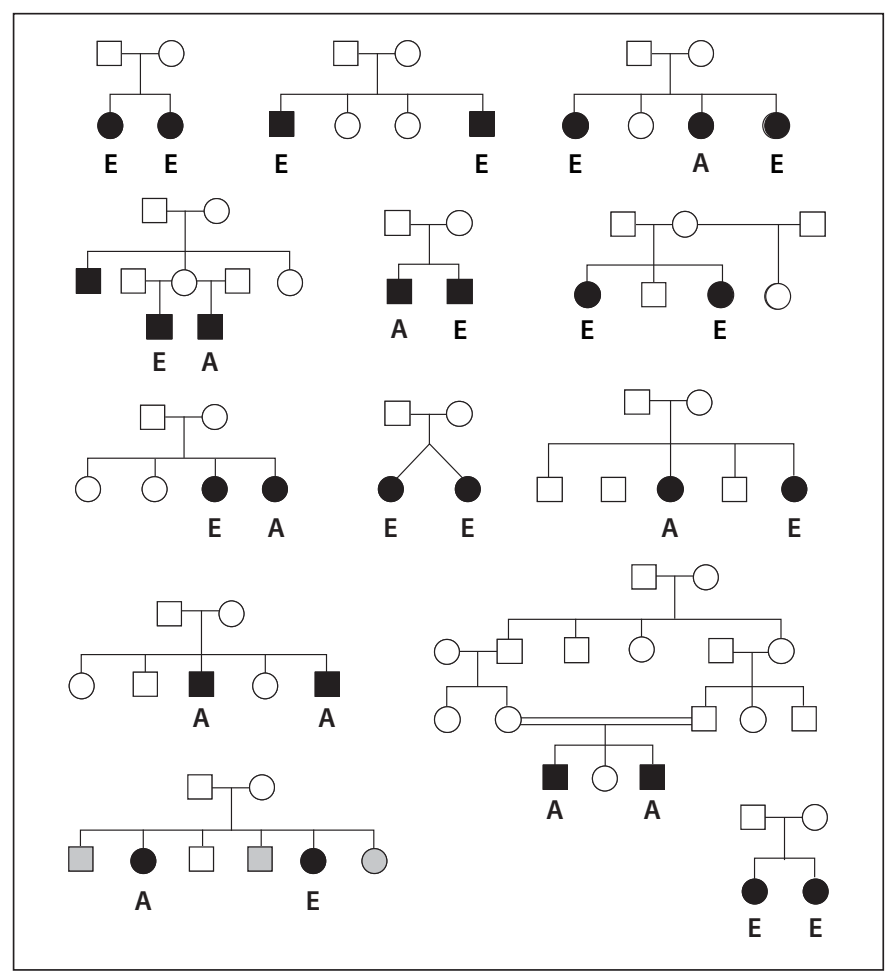

a

Affected sibs $(n=13)$

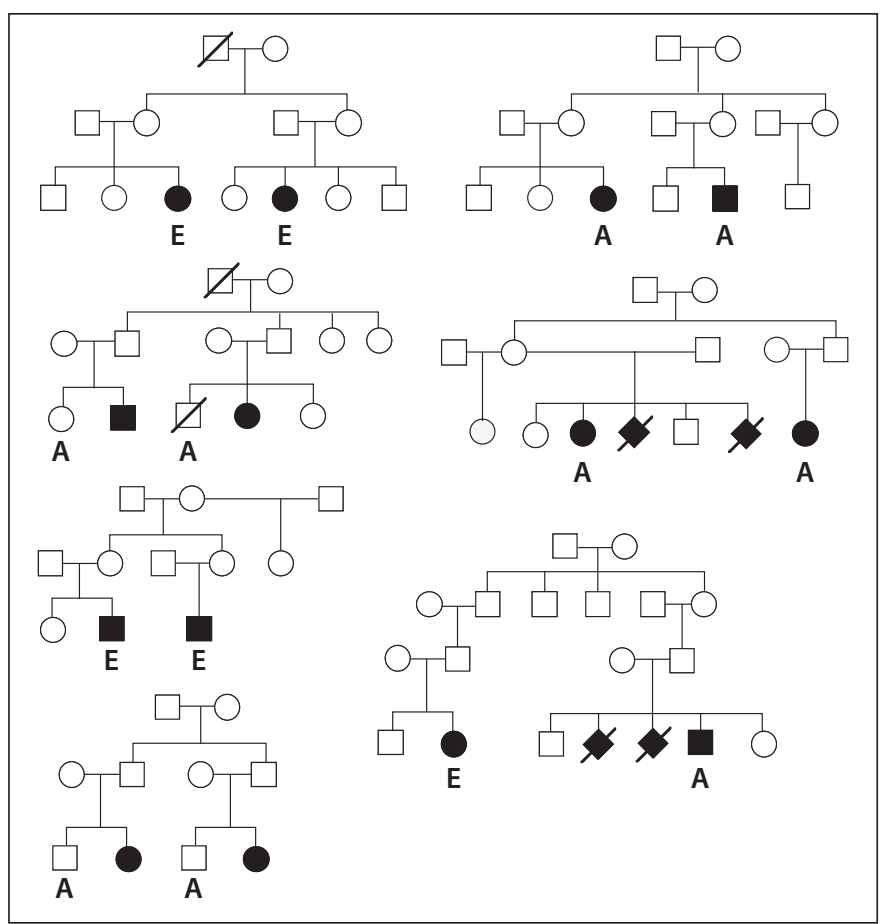

b

Cousins affected $(n=6)$

Fig. 2. Pedigrees and phenotypes of the 32 families with congenital hypothyroidism $(\mathrm{CH})$ caused by thyroid dysgenesis (TD) [1]. a Families with affected first-degree relatives. b Families with affected distant relatives. $\bullet$ = Individuals with $\mathrm{CH}$ revealed

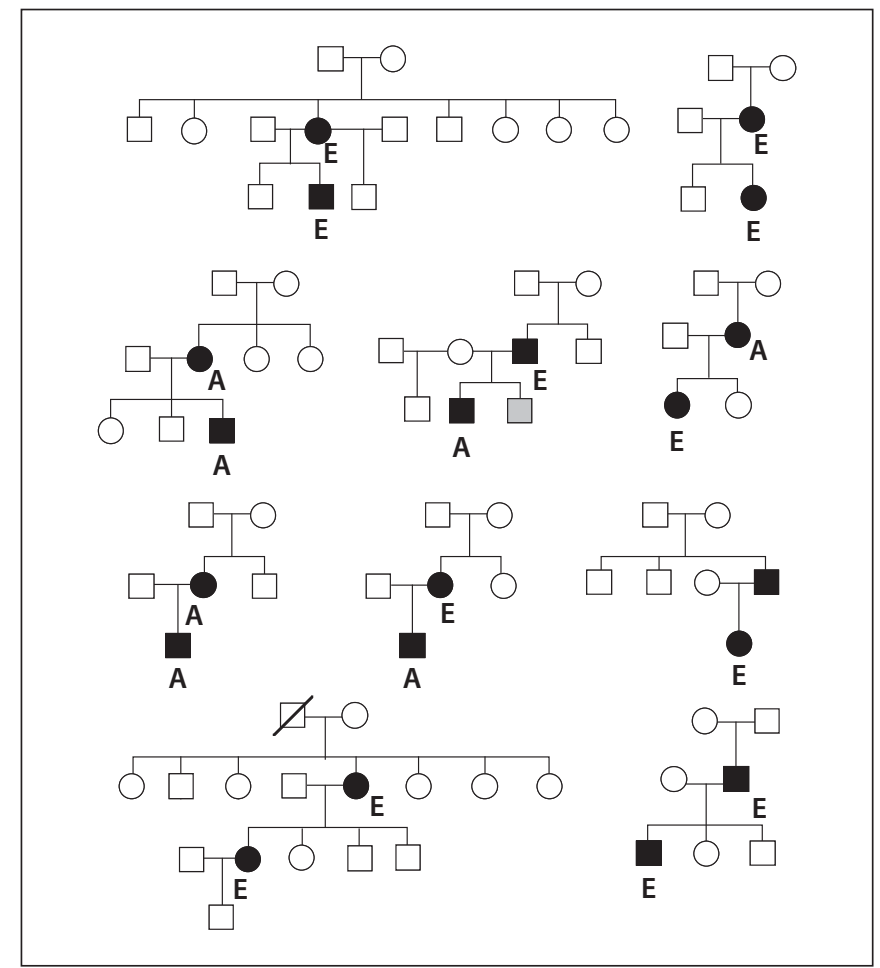

Affected parents and offsprings $(n=10)$

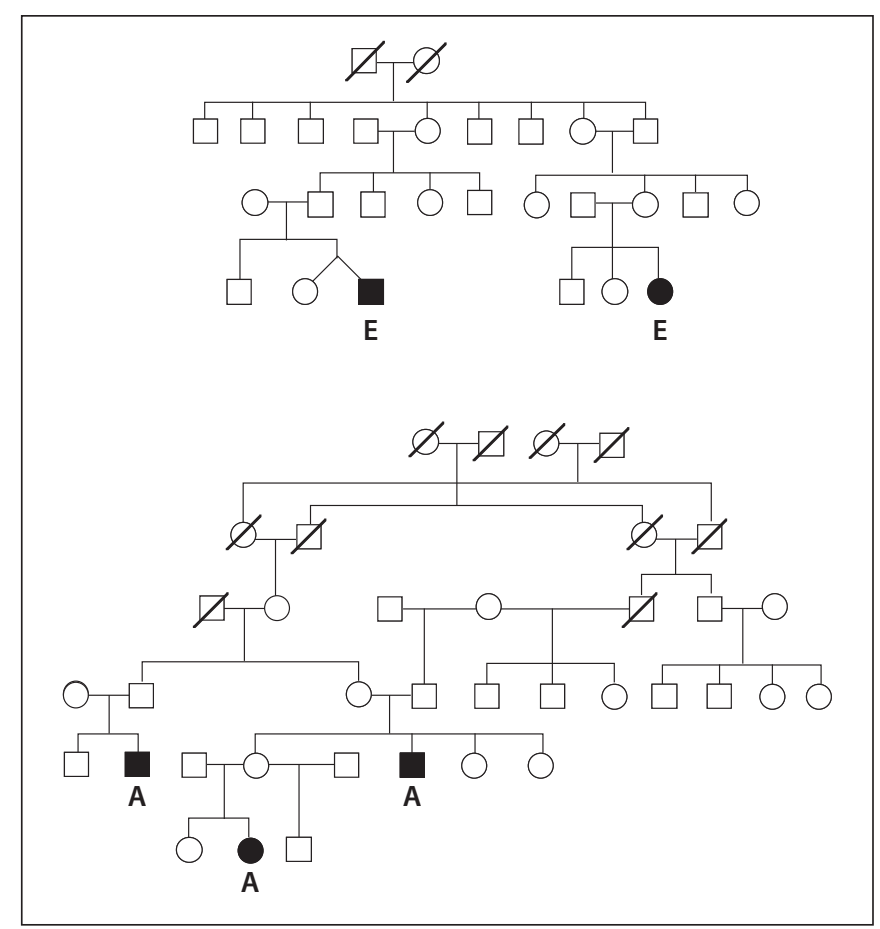

Distant parent affected $(\mathrm{n}=2)$

by TD due to either ectopic thyroid gland (E) or athyreosis (A); $\bigcirc \square=\mathrm{CH}$ patients with a thyroid gland in the normal position. Adapted from [1] with the authorization of Endocrine Society Press. 
Fig. 3. Pedigrees of the 18 families with thyroid dysgenesis including both cases of congenital hypothyroidism and asymptomatic cases [12]. a Families with affected siblings $(\mathrm{n}=8)$. b Families with affected parents and offspring $(\mathrm{n}=10) .{ }^{*}$ Not evaluated subjects. Adapted from [12] with authorization of Endocrine Society Press. a

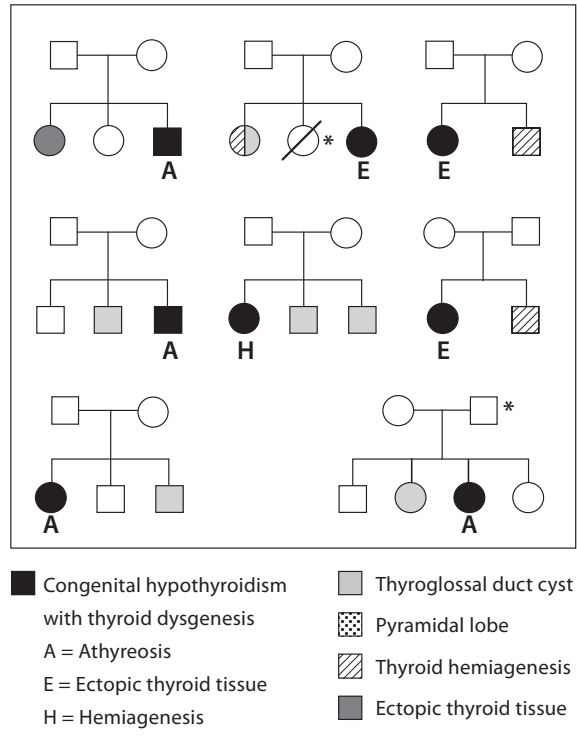

b

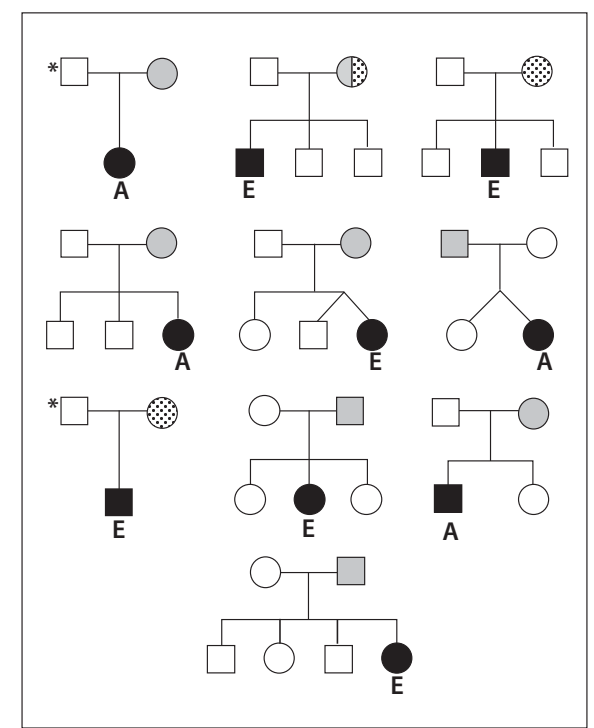

servation is consistent with the ectopic thyroid tissue having a residual function.

As for familial cases of athyreosis, similar proportions of boys and girls were found to have TDA, again suggesting the possible involvement of a sex-modified gene in thyroid development. These data are also consistent with the balanced sex ratio reported in a larger series of patients with symptomatic thyroglossal duct cysts [32].

For the pedigrees reported in this study, the proportions of affected parents (6.5\%) and siblings (10.5\%) with asymptomatic TDA were similar, consistent with a dominant mode of inheritance. Moreover, it was possible to carry out a segregation analysis on this unique sample of families including affected members with either asymptomatic or major forms of TD. This analysis showed the penetrance of the disease to be low, at $21 \%$, and gave a predicted risk of occurrence after an isolated case of $10.5 \%$ for TDA.

Thus, this second familial study demonstrated a high rate of asymptomatic thyroid development abnormalities among first-degree relatives of patients with $\mathrm{CH}$ and TD. Estimates of prevalence were much higher in families with both minor and major forms of TD $(21.4 \%$ of the investigated families) than in families in which the affected members had CH due to TD only. Moreover, this already high proportion of familial cases may nonetheless be underestimated, as only first-degree relatives were evaluated by systematic screening in this study, excluding more distant relatives, who cannot be thoroughly evaluated.
In conclusion, these familial studies have revealed the frequency of familial TD, including asymptomatic forms (TDA), to be relatively high. These observations support the hypothesis of a common origin for defects in embryogenesis, migration, differentiation or growth of the thyroid gland during organogenesis leading to either major forms of TDA with $\mathrm{CH}$ or, more frequently, asymptomatic forms. We cannot entirely exclude the possibility of a role of humoral or environmental factors in thyroid development or of non inheritable post zygotic events, as illustrated by discordance for congenital hypothyroidism in monozygotic twins [33]. However, these data strongly suggest that this disorder has a genetic component and that the predisposing factors display a dominant mode of inheritance, with low penetrance. Recent advances in genetics suggest a polygenic origin for this disorder. However, none of the five candidate genes identified to date appear to play a major role in TD, as demonstrated by a linkage analysis performed in 19 multiplex families with $\mathrm{CH}$ due to TD [34]. A possible involvement of sex-modified factors should be considered in cases of $\mathrm{CH}$ with $\mathrm{TD}$, given the higher frequency of women among patients with $\mathrm{CH}$, which is not found in subjects with TDA. There is thus evidence to suggest that the genetics of TD is complex, possibly having a polygenic/multifactorial basis, and that genetic susceptibility to TD may not follow a simple Mendelian pattern of inheritance. Further studies are required to increase our understanding of the pathophysiology of thyroid dysgenesis. Nevertheless, these findings for familial cases of 
TD indicate that systematic screening for thyroid defects should be carried out in relatives of patients with TD, with or without $\mathrm{CH}$, including the offspring of these patients.

\section{Acknowledgment}

We would like to thank Dr. C. Garel (Hôpital Robert Debré, Paris) for re-reading thyroid ultrasound scans in the familial studies and all the families and pediatricians who took part in these studies.

\section{References}

1 Castanet M, Polak M, Bonaiti-Pellié C, Lyonnet $S$, Czernichow P, Léger J: Nineteen years of national screening for congenital hypothyroidism: familial cases with thyroid dysgenesis suggest the involvement of genetic factors. J Clin Endocrinol Metab 2001;86: 2009-2014.

2 Kaplan EL, Shukla M, Hara H, Ito K: Developmental abnormalities of the thyroid. De Groot LG (ed): Endocrinology. Philadelphia, Saunders, 1994, pp 893-899.

3 De Felice M, Di Lauro R: Thyroid development and its disorders: genetics and molecular mechanisms. Endocr Rev 2004;25:722746.

-4 Olivieri A, Stazi M, Mastroiacovo P, Fazzini C, Medda E, Spagnolo A, De Angelis S, Grandolfo ME, Taruscio D, Cordeddu V, Sorcini M, The Study Group for Congenital Hypothyroidism: A population-based study on the frequency of additional congenital malformations in infants with congenital hypothyroidism (1991-1998). J Clin Endocrinol Metab 2002;87:557-562.

5 Ainger LE, Kelley V: Familial athyreotic cretinism: report of 3 cases. J Clin Endocrinol Metab 1955;15:469-475.

6 Bamforth JS, Hugues I, Lazarus JH, Weaver CM, Harper PS: Congenital hypothyroidism, spiky hair, and cleft palate. J Med Genet 1989;26:49-51.

7 Stäger J, Froesch E: Congenital familial thyroid aplasia. Acta Endocrinol (Copenh) 1981;96:188-191.

-8 Orti E, Castells S, Qazi Q, Inamdar S: Familial thyroid disease: lingual thyroid in two siblings and hypoplasia of a thyroid lobe in a third. J Pediatr 1971;78:675-677.

-9 Kaplan M, Kauli R, Raviv U, Lubin E, Laron Z: Hypothyroidism due to ectopy in siblings. Am J Dis Child 1977;131:1264-1265.

10 Defoer FY, Malher C: Lingual thyroid in two natural brothers. J Clin Invest 1990;13:6567.

11 Castanet M, Lyonnet S, Bonaïti-Pellié C, Polak M, Czernichow P, Léger J: Familial forms of thyroid dysgenesis among infants with congenital hypothyroidism. N Engl J Med 2000;343:441-442.

-12 Léger J, Marinovic D, Garel C, Bonaïti-Pellié C, Polak M, Czernichow P: Thyroid developmental anomalies in first degree relatives of children with congenital hypothyroidism. J Clin Endocrinol Metab 2002;87:575-580.
13 O'Rahilly R: The timing and sequence of events in the development of the human endocrine system during the embryonic period proper. Anat Embryol (Berlin) 1983;166: 439-451.

14 Sprinzl GM, Koebke J, Wimmers-Klick J, Eckel HE, Thumfart WF: Morphology of the human thyroglossal tract: a histologic and macroscopic study in infants and children. Ann Otol Rhinol Laryngol 2000;109:11351139.

15 Macchia P: Recent advances in understanding the molecular basis of primary congenital hypothyroidism. Mol Med Today 2000;6: 36-42.

16 Grant DB, Hulse JA, Jackson DB, Leung SP, Ng WK: Ectopic thyroid: residual function after withdrawal of treatment in infancy and later childhood. Acta Paediatr Scand 1989; 78:889-892.

17 Marinovic D, Garel C, Czernichow P, Leger J: Ultrasonographic assessment of the ectopic thyroid tissue in children with congenital hypothyroidism. Pediatr Radiol 2004;34: 109-113.

18 Gillis D, Brnjac L, Perlman K, Sochett EB, Daneman D: Frequency and characteristics of lingual thyroid not detected by screening. J Pediatr Endocrinol Metab 1998;11:229233.

19 Sauk JJ Jr: Ectopic lingual thyroid. J Pathol 1970;102:239-243.

20 Gallo A, Leonetti F, Torri E, Manciocco V, Simonelli M, DeVincentiis M: Ectopic lingual thyroid as unusual cause of severe dysphagia. Dysphagia 2001;16:220-223.

21 Abramowicz MJ, Duprez L, Parma J, Vassart G, Heinrichs C: Familial congenital hypothyroidism due to inactivating mutation of the thyrotropin receptor causing profound hypoplasia of the thyroid gland. J Clin Invest 1997;99:3018-3024.

22 Gagne N, Parma J, Deal C, Vassart G, Van Vliet G: Apparent congenital athyreosis contrasting with normal plasma thyroglobulin levels and associated with inactivating mutations in the thyrotropin receptor gene: are athyreosis and ectopic thyroid distinct entities? J Clin Endocrinol Metab 1998;83:17711775 .
23 Czernichow P, Schlumberger M, Pomarede R, Fragu P: Plasma thyroglobulin measurements help determine the type of thyroid defect in congenital hypothyroidism. J Clin Endocrinol Metab 1983;56:242-245.

24 Siraj QH, Aleem N, Inam-Ur-Rehman A, Qaisar S, Ahmad M: The pyramidal lobe: a scintigraphic assessment. Nucl Med Commun 1989;10:685-693.

25 Marinovic D, Garel C, Czernichow P, Leger J: Additional phenotypic abnormalities with presence of cysts within the empty thyroid area in patients with congenital hypothyroidism with thyroid dysgenesis. J Clin Endocrinol Metab 2003;88:1212-1216.

26 Bubuteishvili L, Garel C, Czernichow P, Leger J: Thyroid abnormalities by ultrasonography in neonates with congenital hypothyroidism. J Pediatr 2003;143:759-764.

-27 McHenry CR, Walfish P, Rosen IB, Lawrence AM, Paloyan E: Congenital thyroid hemiagenesis. Am Surg 1995;61:634-639.

28 Shabana W, Delange F, Freson M, Osteaux M, de Schepper J: Prevalence of thyroid hemiagenesis ultrasound screening in normal children. Eur J Pediatr 2000;159:456458.

29 Rapidis AD, Economidis J, Goumas PD, et al: Tumours of the head and neck in children: a clinico-pathological analysis of 1,007 cases. J Craniomaxillofac Surg 1988;16:279-286.

30 Issa MM, deVries P: Familial occurrence of thyroglossal duct cyst. J Pediatr Surg 1991; 26:30-31.

31 Rosenberg T, Gilboa Y: Familial thyroid ectopy and hemiagenesis. Arch Dis Child 1980; 55:639-641.

32 Solomon JR, Rangecroft L: Thyroglossalduct lesions in childhood. J Pediatr Surg 1984;19:555-561.

-33 Perry R, Heinrichs C, Bourdoux P, Khoury K, Szotz F, Dussault JH, Vassart G, Van Vliet G: Discordance of monozygotic twins for thyroid dysgenesis: implications for screening and for molecular pathophysiology. J Clin Endocrinol Metab 2002;87:4072-4077.

- 34 Castanet M, Sura-Trueba S, Chauty A, Carre A, de Roux N, Heath S, Leger J, Lyonnet S, Czernichow P, Polak M: Linkage and mutational analysis of familial thyroid dysgenesis demonstrate genetic heterogeneity implicating novel genes. Eur J Hum Genet 2005; 13: 232-239. 